\title{
Uncertainty relationships in the estimation of settlement rates of mobile marine organisms
}

\author{
Luis Giménez \\ School of Ocean Sciences, University of Wales, Bangor, Menai Bridge, Anglesey LL59 5AB, UK
}

\begin{abstract}
Settlement is the process by which pelagic larval stages colonize the sea bottom. Variations in settlement rates can affect population dynamics and community structure. Here I study the importance of spatial and temporal scales of mobility of larvae to define settlement rates of marine species with complex life cycles, and the uncertainty in their estimation. Larvae of mobile marine species (e.g. fish, crabs) arrive at the sea bottom but still swim or crawl for several days, covering considerable distances. This behaviour affects the operational definition of settlement because an observer cannot differentiate between new and old settlers. I model the process of estimation of settlement rate for these organisms incorporating the characteristics of settlers and the process of observation. Settlers are characterised by the temporal and spatial scales of movement within a homogeneous area. The process of observation is characterised by the grain and step (= spatial and temporal resolution) of the sampling design, i.e. the size of the observed site and the time between 2 consecutive observations. As the resolution increases, the uncertainty in the estimation of settlement also increases. There are critical spatial and temporal scales below which the uncertainty is high and evaluation of patterns of settlement is not possible. Uncertainty relationships should be considered in designing sampling schemes to study patterns of settlement without the confounding effect of the subsequent movements of individuals within the settlement habitat. Relationships of this kind may also appear in other fields of ecology.
\end{abstract}

KEY WORDS: Settlement $\cdot$ Recruitment $\cdot$ Larval $\cdot$ Spatial scales $\cdot$ Uncertainty Resale or republication not permitted without written consent of the publisher

\section{INTRODUCTION}

Physical processes operate on organisms, populations, communities and ecosystems at several spatial and temporal scales (Levin 1992). As a consequence, biological rates can vary at several scales and produce scale-dependent patterns of structure. Therefore, conclusions, models and views of structure of communities and ecosystems depend on the scale of observation or experimentation used by ecologists.

Scale-dependent patterns of distribution of many marine species have been related to spatial variations in the rate of larval settlement. This is the rate at which individuals at the end of a larval phase settle on the sea bottom and leave pelagic life; settlement is followed by metamorphosis to a juvenile stage. Settlement rate can vary at various spatial and temporal scales as a consequence of pelagic processes and larval behaviour (e.g. Roughgarden et al. 1988, Jenkins 2005), affecting benthic populations at several scales (Connell 1985, Gaines \& Roughgarden 1985, Raimondi 1990, Caley et al. 1996, Menge 2000).

The estimation of settlement rates in sessile species (e.g. barnacles, ascidians, sessile polychaetes) is done with high precision (e.g. Raimondi 1990, Jenkins et al. 2000, Pineda 2000). In these organisms, settlement is associated with attachment to the bottom surface, meeting the definition given by Keough \& Downes (1982), i.e. settlement is the point at which a larva attaches irreversibly to the substratum (Fig. 1a). Mussels, some sand-dwelling bivalves, polychaetes and ophiuroids (Bayne 1964, Beukema \& de Blas 1989, Hunt \& Scheibling 1997, Hendler et al. 1999, Callaway 2003) may settle and remain in a certain 
area before moving later to adult beds or elsewhere; for these species it is also possible to identify a settler.

However, it may be difficult to identify a settler in mobile species such as some invertebrates from exposed beaches or sandflats (Armonies 1996, Defeo 1996), many decapod crustaceans (Moksnes \& Wennhage 2001, Moksnes et al. 2003, Giménez \& Dick 2007), and reef fish. After reaching a suitable habitat for settlement, but before metamorphosis, crab and fish larvae may move for several days (Fig. 1b). Furthermore, the same problem appears when counting juveniles as settlers, if metamorphosis occurs immediately after settlement. This may happen in reef fish (Valles et al. 2006), but also in bivalves and polychaetes moving by thread drifting (Armonies 1996, Olivier \& Retière 2006) if they start drifting immediately after settlement. Here, new and old juveniles move through the settlement habitat, confusing the measurement of settlement. Therefore, the problem of defining a settler occurs with any stage considered in the measurement of settlement if it has significant mobility. In these cases, it is uncertain whether a sampled individual is a newcomer or is an old settler moving across the benthic habitat.

These types of movements impose a problem for the definition and the estimation of settlement rates and therefore for the study of patterns of settlement in mobile organisms. In this paper, I discuss this problem in the context of patterns and scales of observation. I first focus on the definition of settlement rate. Second, I show that there is uncertainty in the definition of settlement rate that depends on the relationships between the sampling scale and the scale of movement of individuals after they arrive at the settlement habitat. Finally, I discuss the importance of uncertainty in the estimation of settlement rates, how to calculate uncertainty, and potential cases in which similar uncertainties may appear.

\section{DEFINING SETTLEMENT}

Settlement may not be considered an irreversible process in mobile species (Moksnes et al. 2003). An approach to the study of settlement would be to ignore processes operating between the time of arrival of larvae in the sea bottom and metamorphosis, treating this settlement process as a unit. After metamorphosis, individuals can be clearly defined as benthic.

However, it may be important to separate newcomers (i.e. individuals that just arrived in the benthic habitat) from old settlers (i.e. individuals that have been in the benthic habitat for some time). Separation may be justified from an ecological standpoint, since different sets of factors affect the abundance of newcomers (e.g. wind-driven cross-shelf transport) vs. old settlers (e.g. abundance of a benthic predator). Moreover, old settlers may be different from newcomers from a physiological perspective since they have already experienced benthic conditions and substrate cues. Conversely, newcomers are experiencing the benthic habitat for the first time. Therefore, settlement rate in this case should be defined as the number of newcomers sampled per space and time unit.
Fig. 1. Larval settlement in different types of marine species. (a) Sessile species: 2 individuals (circles) settle at different times $\left(t_{1}, t_{2}\right)$ in different sites $(i, j)$ and remain in the original site after some time $\left(t_{3}\right) ;(b)$ mobile species: individuals settle as in the previous example but some individuals migrate to the other site at $t_{3}$. (c) The colonisation rate $\left(C_{t}\right)$ in mobile individuals is a consequence of settlement $\left(S_{t}\right)$ and movements of old settlers $\left(P_{t}\right)$. From the observer's viewpoint, it is not possible to separate the new from old settlers 


\section{Settlement rate, spatial scale and uncertainty}

The settlement rate in mobile species (e.g. crabs, reef fish) must be estimated considering 2 facts: (1) individuals can move within the settlement habitat and (2) an observer cannot tell a newcomer from an old settler. I assume that the settlement rate is estimated within a homogeneous settlement region (e.g. a homogeneous mussel bed), divided into a collection of sites; an observer is trying to measure the rate of settlement in an observed site which is assumed to be devoid of individuals as a starting condition. This situation occurs when settlement is estimated using larval collectors such as those made of blue hog hair (Moksnes \& Wennhage 2001), tuffy bags (Morgan et al. 1982), light traps (Dixon et al. 1999), SMURFs (standard monitoring units for the recruitment of temperate reef fishes; Ammann 2004, Valles et al. 2006) or traps containing natural substratum (Giménez \& Dick 2007). Other methods, such as benthic trawls may not conform to the situation described above. It may be argued that under natural conditions, settlers can either (1) stay at or (2) move out of an observed site. However, as explained above, estimations of settlement rates are usually done using empty collectors as a starting condition, ruling out option (1); obviously, larval movement out of the observed site/collector cannot be observed, ruling out (2).

The settlement rate $S$ (expressed as e.g. ind. $\mathrm{m}^{-2} \mathrm{~d}^{-1}$ ) is defined as the number of newcomers (i.e. individuals that leave pelagic life and settle for the first time) collected during a certain time frame in the focal site characterised by a defined size (see next paragraph). The rate of colonization $C$ is defined as the number of individuals captured at the observed site per area and time unit. $C$ differs from $S$ in that colonization includes newcomers and old settlers.

$S$ can only be estimated through $C$, because $C$ is the number of larvae in the observed site. The estimation of $S$ must consider the fact that old settlers are also present in the observed site, so that $S=C-P$, where $P$ is the number of old settlers, i.e. individuals that colonize the observed site by moving from a previously colonized site (Fig. 1c). Thus, the individuals considered in $P$ have previously settled somewhere else and migrated to a new site within the settlement region.

Since the observer does not know whether a particular collected individual is a newcomer or an old settler, she/he is uncertain about the actual settlement rate. Thus, the uncertainty in any estimation of $S$ should depend on the magnitude of $P$. If $P=0$, then $S=C$, and the settlement rate can be estimated from the colonization rate. This uncertainty $U$ may be defined as the ratio between the number of old settlers and the total number of individuals collected by the observer: $U=$ $P / C$. Thus, uncertainty can vary from 0 to 1 .
It is therefore necessary to calculate $U$, which depends on the number of old settlers that have colonized the observed site. Addressing the problem of uncertainty requires consideration of spatial and temporal scales of biophysical processes (dispersion), biological processes (metamorphosis to a juvenile stage) and sampling design. I first address the problem in space by considering time as a series of steps and assuming that larvae are not metamorphosing; finally I consider the problem of time and incorporate metamorphosis in the estimation of uncertainty.

\section{Uncertainty and space}

Any estimation of settlement involves a sampling design within the settlement region. A sampling design in space can be described in terms of 3 parameters: grain $(\gamma)$, interval $(\beta)$ and extent $(\varepsilon)$ (Dayton \& Tegner 1984, Schneider 1994, Legendre \& Legendre 1998). Grain $\gamma$ is the size of an elementary sampling unit, which defines the resolution of a study. For the present case, $\gamma$ is the size of the observed site, which defines the resolution of the spatial functions $C$ and $P$.

Thus, I consider a 1D settlement region for benthic colonization divided into cells of size $=\gamma$ (Fig. 2a). Here, the benthic colonization of a cell $x=j$ (the observed site) at a time $t$ equals the number of settling larvae plus a fraction of the organisms that settled at time $t-1$ on the adjacent cells $x=j-1$ and $j+1$, and move at a time $t$ to cell $j$. At each event of observation, the colonization rate is:

$$
C_{t}(x=j, \gamma)=S_{t}(x=j, \gamma)+P_{t}(x=j, \gamma)
$$

The fraction of old settlers moving to location $j$ at time $t\left[P_{t}(x=j, \gamma)\right]$ may be defined as the number of individuals on adjacent locations at time $t-1$ multiplied by a transition probability $w(i \rightarrow j)$. Thus,

$$
P_{t}(x=j, \gamma)=\hat{C}_{t-1}(x=j \pm 1, \gamma) \times w(i \rightarrow j), \quad i=j \pm 1
$$

where $\hat{C}_{t-1}(x=j \pm 1, \gamma)=C_{t-1}(x=j+1, \gamma)+C_{t-1}(x=j-1, \gamma)$ since larvae can arrive from both adjacent cells $(j+1$ and j-1). Eq. (2) assumes that the transition probability is independent of the cell in question: this assumption is logical as the equation is developed for a homogeneous settlement region.

Since $U\left[=P_{t}(x=j, \gamma) / C_{t}(x=i, \gamma)\right]$ is the proportion of old settlers present in the observed site, therefore:

$$
U=\frac{\hat{C}_{t-1}(x=j \pm 1, \gamma) \times w(i \rightarrow j)}{C_{t}(x=j, \gamma)}
$$

The uncertainty $U$ should not be $>1$ : in the extreme case, the transition probability $w(i \rightarrow j)=1$, so that we have $U \max =P_{t}(x=j, \gamma) / C_{t}(x=j)$ (see Eq. 2). Since $C=S+P$ (Eq. 1), $C_{t}(x=j, \gamma)=P_{t}(x=j, \gamma)$ when $S=0$ : under this condition $U=U_{\max }=1$. 

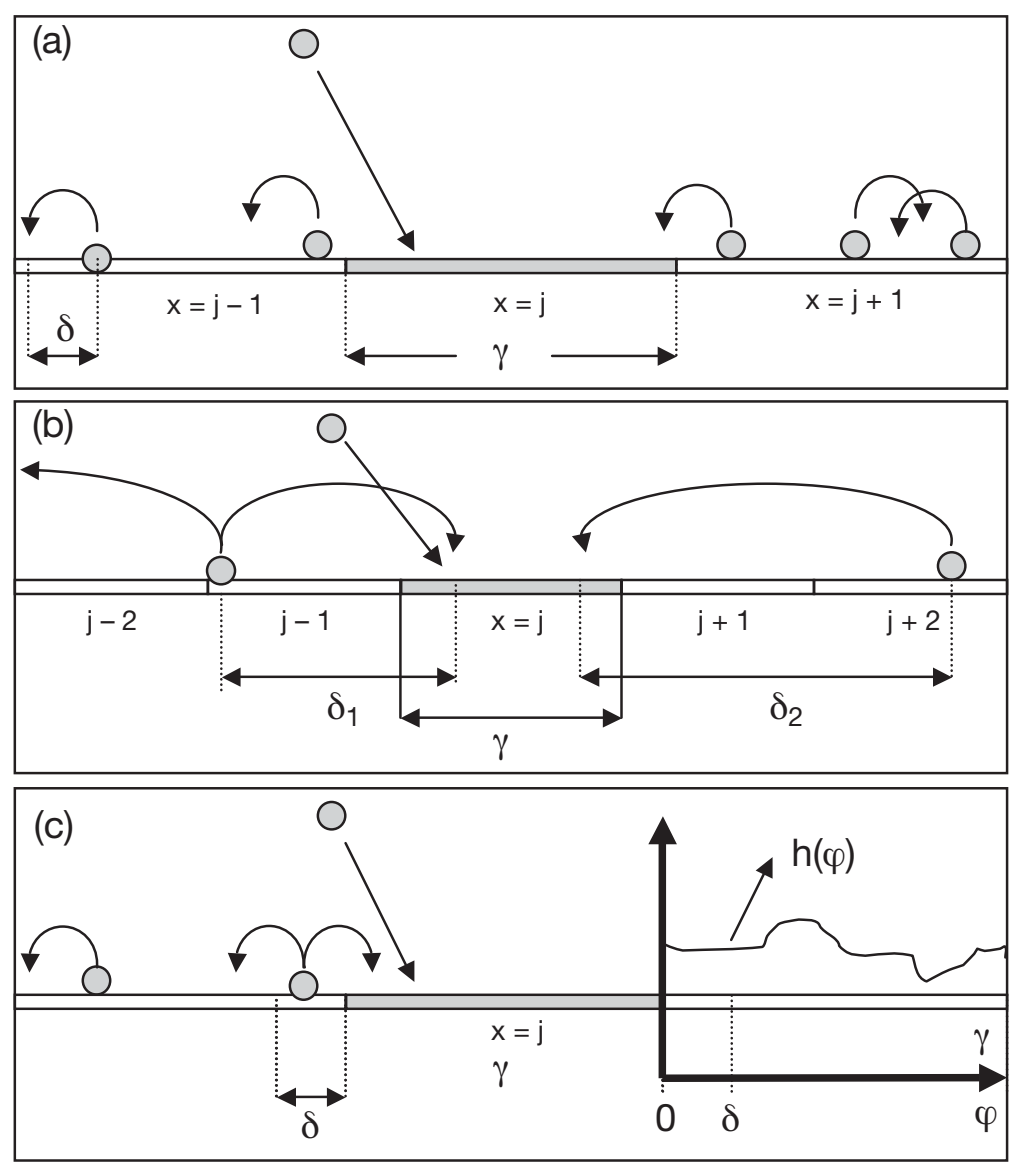

Fig. 2. Importance of sampling scale measured as grain $(\gamma)$ for the uncertainty in the estimation of settlement rate. Circles represent larvae. (a) The substratum is divided into cells of size $\gamma$, and the uncertainty in the settlement rate to $x=j$ is defined using the scale of post-settlement movements $\delta$ of old settlers from adjacent cells (in white) to the observed cell (in gray); (b) alternative post-settlement movements of individuals with different $\delta_{;}$(c) a probability distribution function of larvae, $h(\varphi)$, in adjacent cells according to the spatial axis $\varphi$

Assuming that $\delta$ is the scale of movement of an old settler per unit time step, which is independent of its spatial position and direction of movement (Fig. 2), it is then possible to express the transition probability $w$ as a function of $\delta$ and $\gamma$ as follows:

(A) If $\delta=\gamma$, larvae may either move to cell $j$ or to the opposite cell (Fig. 2b, left side). If movement is random, the transition probabilities do not depend on the direction of movement. There are 2 possibilities: $\left(\mathrm{A}_{1}\right)$ all individuals move to any of the 2 adjacent cells $(i=j$ or $i=j-2$ in Fig. 2 b) so that $w(i \rightarrow j)=1 / 2 ;\left(\mathrm{A}_{2}\right)$ larvae either move to any of the 2 adjacent cells or remain in the cell $(i=j-1$ in Fig. $2 b)$ so that $w(i \rightarrow j)=1 / 3$.

(B) If $\delta>\gamma, w(i \rightarrow j)=k$, where $0 \leq k \leq 1$. One must consider other cells farther from the observed site (e.g. cell $j+2$ in Fig. $2 b$, right side). Considering these cells, $\hat{C}_{t-1}(x=j \pm i, \gamma)=\sum_{x} C_{t-1}(x \neq j, \gamma)$ in Eq. (2). The additional number of larvae arriving at the observed cell is also incorporated in $C_{t}(x=j)$ in Eq. (3) so that $U \leq 1$.

(C) If $\delta<\gamma$, it should be possible to define at least one sub-cell of size $\delta$ within the cell $i$ so that any individual within this sub-cell is able to move to $j$ (Fig. 2c, left side). Thus, assuming that the individuals are evenly distributed across the cells $j-1$ and $j+1$, the fraction of old settlers moving to location $j$ at time $t$ becomes:

$$
P_{t}(x=j, \gamma)=\hat{C}_{t-1}(x=j \pm 1, \gamma) \times k \times \frac{\delta}{\gamma}
$$

This equation also applies if $\delta=\gamma$ (where $\lambda$ is the time step) because it leads to $w(i \rightarrow$ $j)=k$. Therefore, we have:

$$
U_{t}=\frac{\hat{C}_{t-1}(x=j \pm 1, \gamma) \times k \times \delta}{C_{t}(x=j) \times \gamma}
$$

Defining the ratio between colonization in the observed cell at time $t$ and the one in the surrounding cells at time $t-1$ as $R_{t}=\hat{C}_{t-1}(x=j \pm 1, \gamma) / C_{t}(x=j), U_{t}$ becomes:

$$
U_{t}=\frac{R_{t} \times k \times \delta}{\gamma}
$$

Eq. (5) shows that the uncertainty in the measurement of settlement rate increases as $\gamma^{-1}$ and $\delta$ increase until it reaches a maximum value of 1 . Since $\delta$ is the scale of movement of old settlers within the settlement habitat and $\gamma$ is the grain of the sampling design, an increase in spatial resolution is achieved through a reduction of $\gamma$, but this increase leads to a higher uncertainty $U$ about the spatial variation in the settlement rate. Therefore, any increase in spatial detail about the patterns of colonization increases the uncertainty in the estimation of settlement rate. Conversely, any reduction in the uncertainty of the estimation of settlement rate is achieved at the expense of losing spatial detail, i.e. by increasing $\gamma$. Given an arbitrarily defined level of certainty, there is a limit of spatial resolution beyond which settlement cannot be operationally defined, because the uncertainty about the origin of the sampled larvae will be above the defined level of $U$. Thus, the definition of settlement for mobile species is related to the scale of observation by means of an uncertainty relationship.

The general results discussed here should not change if we relax the assumptions of even distribution of organisms in each cell or constant transition probabilities. For instance, generalizing for any distribution of individuals within the cells $j+1$ and $j-1$, the fraction of old settlers moving to location $j$ at time $t$ becomes: 


$$
P_{t}(x=j, \gamma)=\hat{C}_{t-1}(x=i, \gamma) \times k \times \int_{0}^{\delta} h(\varphi) d \varphi
$$

where $h(\varphi)$ is a probability density function describing the distribution of organisms in the cells $j+1$ and $j-1$ and depending on the distance $\varphi$ from the cell $j$ (Fig. 2c, right side). The distance $\varphi$ can vary from 0 to $\gamma$, but we are interested in the fraction of larvae that are able to travel a distance $\delta$ and colonize the cell $j$. If the distribution is homogeneous, then $h(\varphi)=1 / \gamma$ and therefore the integral of Eq. (6a) equals $\delta / \gamma$, which takes us back to Eq. (4). Defining the last term in Eq. (6a) as:

$$
\int_{0}^{\delta} f(\varphi) d \varphi=\left(\frac{\delta}{\gamma}\right)^{-1} \times \int_{0}^{\delta} h(\varphi) d \varphi
$$

$P_{t}$ becomes:

$$
P_{t}(x=j, \gamma)=\hat{C}_{t-1}(x=i, \gamma) \times k \times \frac{\delta}{\gamma} \times \int_{0}^{\delta} f(\varphi) d \varphi
$$

where $\int f(\varphi) d \varphi$ is a correction factor that depends on $h(\varphi)$. For the case of a homogeneous distribution, the correction factor is 1 and Eq. (6) becomes Eq. (4).

If the grain of the study is much larger than the necessary grain to estimate $h(\varphi)$, it is not possible to estimate the correction factor. However, even if the correction factor is unknown, it is clear that assuming a constant $\delta$, an increase in the grain $\gamma$ leads to a decrease in the uncertainty in the estimation of settlement rate.

In a $2 \mathrm{D}$ system, the fraction of old settlers that are able to invade a cell is proportional to $(\delta / \gamma)^{2}$. Thus, defining $\varphi$ in the $x$ and $y$ spatial directions, $P_{t}$ becomes:

$$
\begin{aligned}
& P_{t}(x=j, \gamma)= \\
& \hat{C}_{t-1}(x=i, \gamma) \times k \times g \times\left(\frac{\delta}{\gamma}\right)^{2} \times \iint_{0} f(\varphi x \varphi y) d \varphi x d \varphi y
\end{aligned}
$$

where $g$ is a proportionality constant. Again, the main conclusion is that a decrease in the uncertainty of the estimation of settlement is gained only at the expense of losing spatial detail.

\section{Uncertainty and time}

There are 2 issues that must be treated in relation to time: (1) dispersion - the dispersal region of a population of old settlers increases with time; (2) development - individuals metamorphose as time passes. There is of course, a third important process, mortality, which is not discussed here. Due to high mortality, settlement studies tend to use sampling at high frequency (e.g. every 24 to $25 \mathrm{~h}$ ); this issue has been extensively discussed elsewhere (e.g. Caley et. al 1996, Giménez 2004). Here, I discuss the issue of dispersion and development. In this context, the importance of the time step will be introduced for the 1D case.

\section{Dispersion}

Eq. (4) is defined, in terms of the time step $\lambda$ as follows:

$$
P_{t}(x=j, \gamma)=\hat{C}_{t-\lambda}(x=j \pm 1, \gamma) \times k \times \frac{\delta}{\gamma}, \delta<\gamma
$$

For a time step $n \times \lambda$, it is possible to define a cell of size $n \times \gamma$. In terms of a time step $\lambda^{\prime}=n \times \lambda$, the scale of movement is $\delta^{\prime}=n \times \delta$. The process can be described in terms of a single step, between time $t$ and time $t+n \times$ $\lambda$, using $\gamma^{\prime}=n \times \gamma$, so that

$$
P_{t}\left(x=j, \gamma^{\prime}\right)=\hat{C}_{t-\lambda^{\prime}}\left(x=j \pm 1, \gamma^{\prime}\right) \times k \times \frac{\delta^{\prime}}{\gamma^{\prime}}, \delta^{\prime}<\gamma^{\prime}
$$

Therefore, an increment of a time step leads to a decrement in the spatial resolution because $\gamma<\gamma^{\prime}$. To increase the spatial resolution of a study without increasing the uncertainty, it is necessary to increase the temporal resolution of the sampling design. This leads to a decrease in the scale of movement of old settlers and in cell size. In this case, there is consequently no trade-off between the increment in precision in the temporal pattern and the uncertainty in defining settlement rate. The uncertainty is reduced by increasing the temporal resolution of the study.

\section{Development}

As time passes, larvae metamorphose to a juvenile stage. If $\tau$ is the time required by a settled individual to metamorphose, then the proportion of remaining larvae $P_{\mathrm{nm}}$ can be defined as: 1 - proportion of metamorphosed individuals. If the distribution of time to metamorphosis follows a negative exponential function, then the cumulative proportion of metamorphosed individuals between 0 to $\tau$ time units is $\left(1-\mathrm{e}^{-\lambda / \tau}\right)$ given a sampling interval or time step $\lambda$. Therefore, the proportion of remaining larvae $P_{\mathrm{nm}}$ is $\mathrm{e}^{-\lambda / \tau}$. If metamorphosis and dispersion are independent events, $P_{t}$ for the $1 \mathrm{D}$ case becomes:

$$
P_{t}(x=j, \gamma)=\hat{C}_{t-\lambda}(x=j \pm 1, \gamma) \times k \times \frac{\delta}{\gamma} \times \mathrm{e}^{-\lambda / \tau}
$$

so that $U_{t}$ becomes:

$$
U_{t}=R_{t} \times k \times \frac{\delta}{\gamma} \times \mathrm{e}^{-\lambda / \tau}
$$

Therefore, an increment in $\tau$ leads to an increase in $P_{t}$ and in the uncertainty of the definition of settlement. There is now a new trade-off between the effects produced by dispersal and those produced by metamorphosis. A decrease in the uncertainty in the estimation of settlement is gained at the expense of losing temporal resolution. 


\section{DISCUSSION}

Research on settlement rates addresses the issues of temporal and spatial variation, the controlling factors and the potential consequences for population and community dynamics. However, this study is about whether we can accurately define and estimate settlement at all. This study shows that there are critical scales below which it is not possible to answer questions about patterns of larval settlement: below these scales settlement cannot be defined with certainty. Uncertainties in the estimation of settlement rates occur in species with a settling stage that remains highly mobile in the settlement habitat and that do not attach irreversibly to the substrate (e.g. decapod crabs, fish, some mollusks and polychaetes). In barnacles, for instance, settlement is an irreversible process associated with metamorphosis to a sessile benthic phase. In addition, settled cypris larvae may metamorphose in $<2$ d (e.g. Semibalanus balanoides; Jenkins et al. 2000). On the contrary, mobile species may disperse after settlement and spend 5 to $6 \mathrm{~d}$ as larvae in the settlement habitats (e.g. Carcinus maenas; Moksnes et al. 2003, Giménez \& Dick 2007). Thus, settlement of mobile species cannot be studied without incorporating the critical spatial and temporal scales in the sampling design.

There are 2 main sets of questions arising from the description of uncertainty relationships: (1) Can we apply the equations in order to predict a level of uncertainty, given a sampling design? Can we plan a sampling protocol for a desired level of uncertainty? (2) Are there other, still unexplored, uncertainty relationships in ecology? How do known uncertainty relationships compare with the one described here? These questions are addressed below.

\section{Applications}

Uncertainty, in terms of $U$, should be used to define a sampling design or determine the scale/grain at which it is possible to make conclusions about settlement. Difficulties may arise from lack of information on parameters of the uncertainty equations. However, as I show below, conservative estimates can be obtained so that $U$ is low.

The uncertainty can be set to a desired critical level in order to calculate the unknown variables $(\gamma$ and $\lambda$ ) using the parameters of the equation $\left(R_{t}, P_{n m}, \delta\right.$ and $\left.k\right)$. The equation has 2 types of parameters: (1) $R_{t}$ and $P_{\mathrm{nm}}$ describe the patterns of colonization rate and proportion of larvae metamorphosing to a juvenile stage; $R_{t}$ can be calculated from the colonization rates estimated at several sites and times; $P_{\mathrm{nm}}$ can be calculated by rearing larvae in the laboratory until metamorphosis. (2) $\delta$ and $k$ describe the behaviour and extent of larval movement and need to be addressed in a separate study or estimated from the literature.

The first step is therefore to establish a desired critical level of uncertainty for which one wants to estimate the scales, i.e. critical $\gamma\left(=\Gamma_{C}\right)$ and critical $\lambda\left(=\Lambda_{c}\right)$. As an example, I assume that $U=0.10$ is a satisfactory level of uncertainty, although by convention, other levels (e.g. $0.05)$ can be used. Below I follow the next steps considering uncertainty in space and time separately.

\section{Uncertainty in space}

The objective here is to calculate the $\Gamma_{0.10}$, i.e. the grain of the sampling design so that $U \leq 0.10$. I assume a situation in which a sampling scheme is necessary to estimate spatial patterns of settlement along a coast line. For this purpose, I use Eq. (9) assuming an even distribution of larvae within each sampling unit. For $\mathrm{U}=0.10: k \times R_{\mathrm{t}} \times \delta / \Gamma_{0.010} \times P_{\mathrm{nm}}$ and therefore: $\Gamma_{0.10}=$ $k \times \delta \times R_{\mathrm{t}} / 0.10 \times P_{\mathrm{nm}}$.

The next step is to consider $R_{t}$ and $P_{n m}$. If the observer wants to establish the critical scales before the study is conducted, she/he will need to make assumptions about these parameters. The simplest approach is to assume $R_{t}=1$ and $P_{\mathrm{nm}}=1$. Setting $R_{t}=1$ means that all the temporal and spatial variations in colonization rates are smoothed out because $R_{t}=1=\hat{C}_{t-1}(x=j \pm 1, \gamma) / C_{t}(x=j)$. Setting $P_{\mathrm{nm}}=1$ means that the time to metamorphosis is so long that all individuals remain in the larval stage during the study period. Under this situation, $\Gamma_{0.10}=k \times \delta / 0.10$, which is applied for the whole study.

Alternatively, the observer could sample larvae at the smallest spatial scale allowed by logistic constraints, estimate $R_{t}$ and $P_{\mathrm{nm}}$ in parallel with the study and calculate the critical scales thereafter. The ratio $R_{t}$ will vary in time according to the variations in the colonization rates and will lead to variations in $\Gamma_{0.10}$ : during the start of settlement peaks, when the colonization rate at time $t-1$ is lower than the colonization rate at time $t, R_{t}<1$ and $\Gamma_{0.10}$ is small; the opposite situation leads to $\mathrm{R}>1$; other things being equal, $\Gamma_{0.10}\left(R_{t}>1\right)>$ $\Gamma_{0.10}\left(R_{t}<1\right) . P_{\mathrm{nm}}$ is calculated from laboratory rearing of larvae: after a time $\lambda$ in the laboratory, the proportion of remaining larvae $P_{\mathrm{nm}}=1$, and we have: $\Gamma_{0.10}=k \times \delta$ $\times R_{\mathrm{t}} / 0.10$, as explained in the next section.

The last step is determining $k$ and $\delta$. If the settlement area is homogeneous, then there is no reason for old settlers to prefer to leave the colonized sites for any particular new site. Under this situation, the most conservative estimate of $\Gamma_{0.10}$ is obtained if $k=0.5$. If information about the parameter of larval movement $\delta$ is 
available, then it is possible to finally calculate $\Gamma_{0.10}$. For instance, assuming $\delta=100 \mathrm{~m}$ for $\lambda=1 \mathrm{~d}$ : an estimation before the study gives: $\Gamma_{0.10}=0.5 \times 100 / 0.10 \times 1=$ $500 \mathrm{~m}$. A study with a grain of e.g. $500 \mathrm{~m}$ can be done by random sampling in several shores of $500 \mathrm{~m}$ extent each. The observer is able to compare variations in the average settlement rate among sectors, looking at variations in colonization rate.

In a real situation, the most problematic parameter in the use of the uncertainty equations is the scale of larval movement $\delta$. As a conservative estimate, this parameter may be equated to the maximum larval swimming speed or to the maximum current displacement in the study area. The scale of movement of individuals may depend on the type of larvae (Shanks 1995). Environmental conditions (e.g. hydrodynamics, topography, temperature) should also be important, because most larvae cannot swim against currents. Assuming $5 \mathrm{~cm} \mathrm{~s}^{-1}$ for the speed of movement of fish and crustacean larvae and for the speed of coastal currents (Shanks 1995), we have a scale of movement of $4320 \mathrm{~m} \mathrm{~d}^{-1}$. This gives the most conservative estimate of the grain: $\Gamma_{0.10}=21.6 \mathrm{~km}$. Based on theoretical calculations of the dispersal distance of Pectinaria koreni juveniles living in sandflats (321 $\mathrm{m}$ in $9 \mathrm{~min}$ at maximum tidal current speeds of $60 \mathrm{~cm} \mathrm{~s}^{-1}$; Olivier \& Retière 2006), and assuming that juveniles move only for $9 \mathrm{~min}$ in a whole day, we get $\Gamma_{0.10}=1600 \mathrm{~m}$. These estimates are quite conservative even under the unrealistic assumption of juvenile bivalves moving only for $9 \mathrm{~min}^{-1}$. However, real distances might be much smaller than those calculated theoretically, depending on the species and the habitat. Larvae may not swim at constant speeds and in a single direction during a whole day; intertidal species will be transported only during periods of high tide, reducing $\Gamma_{0.10}$ according to the tidal level.

Behaviour and habitat patchiness should also be important: for instance, in a system composed of isolated reefs, fish settlers could move freely for long distances within the reef, but may modify their behaviour with respect to movements across reefs. For the latter case, the parameter $k$ would be $<<0.5$, reflecting a smaller fraction of individuals actually choosing to travel to another reef. Therefore, the scales of movement could be much shorter. However, more research on the actual distance of larval/juvenile dispersal is necessary in order to develop a sampling scheme for a particular level of uncertainty.

\section{Uncertainty in time}

For a sampling scheme in time, it is necessary to calculate the value $\lambda=\Lambda_{0.10}$, i.e. the time step associated with a critical level of uncertainty (if $U=0.10$, then we have $\Lambda_{0.10}$ ). In this case, the uncertainty reduces the parameter describing processes related with time, that is $P_{\mathrm{nm}}$. Parameters describing spatial processes are set to 1 , so that $0.10=P_{\mathrm{nm}}$. The parameter $\Lambda_{c}$ is estimated from the cumulative distribution of individuals metamorphosing in the laboratory: $\Lambda_{0.10}$ is the time after which $90 \%$ of the larvae have metamorphosed to the juvenile stage. If the observer wants to calculate $\Lambda_{0.10}$ before conducting the study, then information about the duration of the settling stage could be used. However, again, here the best strategy is improve the calculation done before the study by (1) using a highfrequency sampling (e.g. once per day), (2) performing the laboratory metamorphosis assay in parallel with the sampling and (3) calculating $\Lambda_{0.10}$ after that particular study.

As an example, I use data from the shore crab Carcinus maenas, a key benthic species of north European coasts: here samples are collected every day. An estimation of $\Delta_{0.10}$ before the study can be done with the stage duration of the megalopa, and gives a $\Lambda_{0.10}$ of $\sim 15 \mathrm{~d}$. However, data collected from Helgoland (North Sea, German Bight: June to September 2003) and Menai Straits (Irish Sea, North Wales: June 2008) show that $\Lambda_{0.10}$ is much shorter and varies considerably in space and time: $\Lambda_{0.10 \text { Helgoland }}=$ $6 \mathrm{~d}$ (Fig. 3a); $\Lambda_{0.10 \text { North Wales }}=3 \mathrm{~d}$ (Giménez unpubl.). The latter values compare favourably with the value of $15 \mathrm{~d}$ available before the study. For the case of Helgoland, Giménez \& Dick (2007) used spectral analysis to determine the scales of temporal variability in colonization (Fig. 3b) and concluded that no inferences could be made about variability in rates at scales $\leq 6 \mathrm{~d}$. At longer scales, the uncertainty to define a settler is low and variations in colonization rates occurring at scales of 10,20 and $30 \mathrm{~d}$ can be attributed to variations in settlement rate. However, using the theoretical value of $15 \mathrm{~d}$ would not enable analysis of variations in settlement at the scale of $10 \mathrm{~d}$. Here, the correct conclusion is that variations in colonization rates at scales $\geq 10 \mathrm{~d}$ can be interpreted as variations in settlement rate. However, it is wrong to conclude that $10 \mathrm{~d}$ is the appropriate scale of sampling; sampling should be done daily in order to reduce the effects of benthic mortality.

A further reduction in the uncertainty with respect to time can be achieved when it is possible to differentiate early from late larvae. Megalopae of decapod crustaceans can be classified according to moulting cycle events using e.g. Drach's classification (Anger 2001). If late larvae can be defined as old settlers, then it is possible to use early larvae for the estimation of settlement. In this case, one could define $P_{\mathrm{nm}}$ as the proportion of animals remaining in the early stage thereby reducing $\Lambda_{C}$. 
In summary, the best strategy to approach the problem of uncertainty is to (1) search for theoretical values of critical scales before the survey (e.g. duration of the megalopa stage), but (2) run parallel laboratory assays in order to estimate (and hopefully reduce) the critical scales for that particular survey. This procedure is not a statistical method of hypothesis testing; here, with the exception of $U$, there is no need to specify parameter values a priori. The procedure of estimating and using critical scales of uncertainty can be compared to an observer attempting to measure the length of an object with a ruler, but in a situation where the object modifies the properties of the ruler (i.e. whether the ruler will be giving lengths in $\mathrm{mm}$ or $\mathrm{cm}$ ).
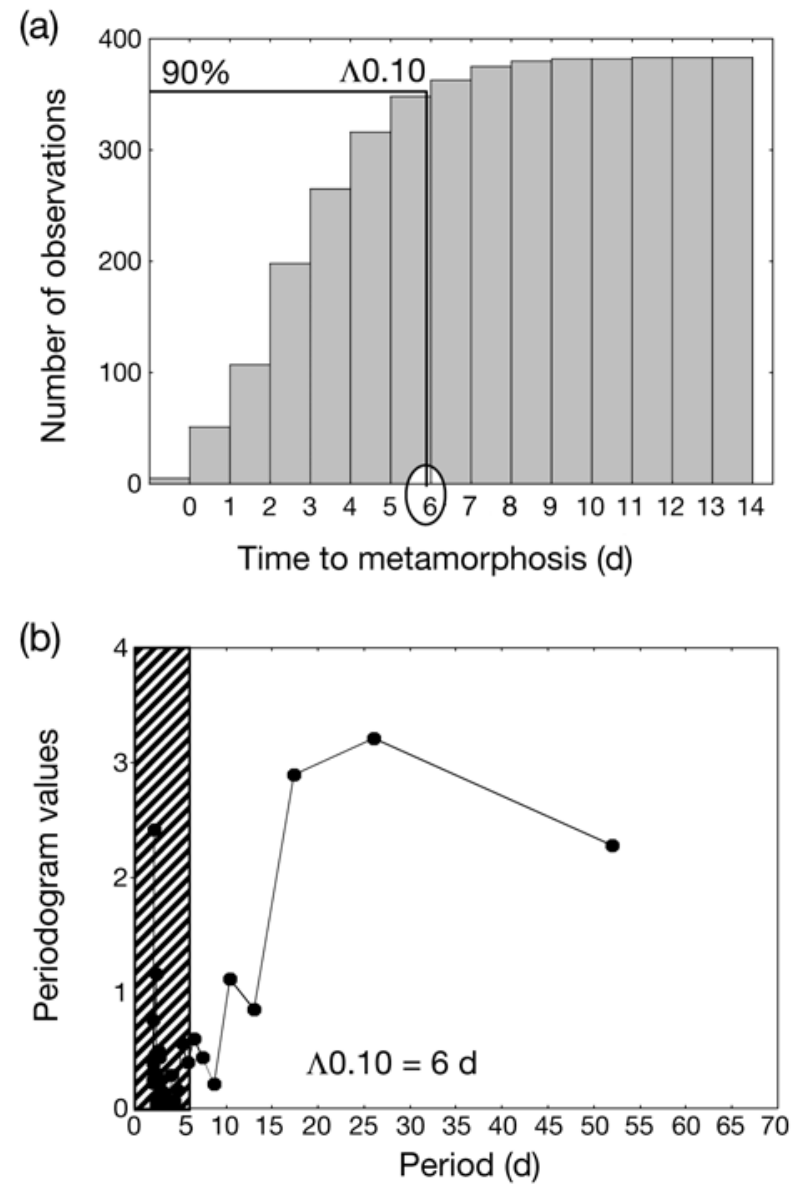

Fig. 3. Carcinus maenas. Estimation of the critical time scale of uncertainty in settlement for the shore crab. (a) Cumulative distribution of time to metamorphosis in megalopa collected in Helgoland (North Sea) in 2003. The critical scale $\Lambda_{0.10}=6 \mathrm{~d}$ is defined as the time required for $90 \%$ of the collected larvae to metamorphose to the first juvenile stage. (b) Spectral analysis of the rate of larval colonization: oscillations of periods $\leq 6 \mathrm{~d}$ (hatched area) cannot be attributed with certainty to variation in settlement rates. Larvae $(n=383)$ were collected every day from traps deployed in the intertidal zone. Collected larvae were reared under controlled conditions of temperature and salinity and ad libitum feeding (see Giménez \& Dick 2007 for further details)

\section{Uncertainty in settlement and other uncertainties}

From an ecological standpoint, the problem of uncertainty may appear when determining the origin of organisms with at least one mobile life phase, such as when evaluating how open populations are. The evaluation of whether organisms recruit in the same population leads to a problem of uncertainty. Assuming a series of populations of a species with a mobile life phase such as reef fish, larval stages released to the coastal waters may recruit in the same population. Once a recruit is sampled, there is uncertainty on whether or not this individual originated from the same population. Here, the central point is the ratio between the distance among populations and the scale of larval dispersal: self recruitment can be assessed at large scales (e.g. 10-100 km in the marine habitat; see Cowen et al. 2006 for estimations of larval dispersal). This problem may be addressed by identifying the origin of organisms using tags (Di Bacco \& Levin 2000, Jones et al. 1999, Levin 2006) or using mathematical modelling to predict the level of self recruitment (Irisson et al. 2004, Cowen et al. 2006, Levin 2006). However, at least in crustaceans, tags cannot yet be used to distinguish individuals of different ages. We therefore need more research on the physiology of larval development in order to understand patterns of settlement at short temporal and spatial scales. This information could be used to build a model of larval behaviour in benthic habitats in order to have a better estimation of the scale of horizontal displacement.

From a general standpoint, the problem of uncertainty in the estimation of settlement rate is not the same as in quantum mechanics (Heisenberg 1927, 1959; cf. his comments on the measurement of momentum and position of an electron by microscope) or in studies on herbivory (Cahill et al. 2001). In the latter cases, the observation method modifies the observed system and thus its observed response. The uncertainty relationship in settlement rate calculation arises from the necessity to consider the scale of movement of the settling individuals. However, the example of settlement rate shares a common property with that of physics in that there are critical scales. For settlement rate, the critical scale defines a limit beyond which spatial or temporal patterns of settlement cannot be estimated because settlement cannot be defined with certainty.

In conclusion, the problem of scale in combination with the study of motile organisms leads to the problem of estimation and definition of settlement rates. Movement of settling stages limits the study of settlement rates and the physical and biological processes affecting it. If other ecological rates are as affected as settlement rate, the definition of critical scales should help ecologists to define the kind of questions that can be addressed in a particular study. 
Acknowledgements. This paper benefited from discussions with K. Anger and V. Grimm.

\section{LITERATURE CITED}

Ammann A (2004) SMURFs: standard monitoring units for the recruitment of temperate reef fishes. J Exp Mar Biol Ecol 299:135-154

Anger K (2001) The biology of decapod crustacean larvae. Swetz \& Zeitlinger, Lisse

Armonies W (1996) Changes in distribution patterns of 0group bivalves in the Wadden Sea: byssus-drifting releases juveniles from the constraints of hydrography. J Mar Res 35:323-334

Bayne B (1964) Primary and secondary settlement in Mytilus edulis L. (Mollusca). J Anim Ecol 33:513-523

Beukema J, de Blas J (1989) Tidal-current transport of threaddrifting postlarval juveniles of the bivalve Macoma balthica from the Wadden Sea to the North Sea. Mar Ecol Prog Ser 52:193-200

Cahill J, Castelli J, Casper B (2001) The herbivory uncertainty principle: Visiting plants can alter herbivory. Ecology 82: 307-312

Caley M, Carr M, Hixon M, Hughes T, Jones G, Menge B (1996) Recruitment and local dynamics of open marine populations. Annu Rev Ecol Syst 27:477-500

Callaway R (2003) Juveniles stick to adults: recruitment of the tube-dwelling polychaete Lanice conchilega Pallas, 1766. Hydrobiologia 503:121-130

Connell JH (1985) The consequence of variation in initial settlement vs. post-settlement mortality in rocky intertidal communities. J Exp Mar Biol Ecol 93:11-45

Cowen RK, Paris CB, Srinivasan A (2006) Scaling of connectivity in marine populations. Science 311:522-527

Dayton P, Tegner M (1984). The importance of scale in community ecology: a kelp forest example with terrestrial analogs. In: Price P, Slobodchikoff C, Gaud W (eds) A new ecology: new approaches to interactive systems. John Wiley \& Sons, New York, p 457-481

Defeo O (1996) Recruitment variability in sandy beach macroinfauna: much to learn yet. Rev Chil Hist Nat 69:615-630

Di Bacco C, Levin L (2000) Development and application of elemental fingerprinting to track marine invertebrate larvae. Limnol Oceanogr 45:871-880

Dixon P, Milicich M, Sugihara G (1999) Episodic fluctuations in larval supply, Science 283:1528-1530

> Gaines S, Roughgarden J (1985) Larval settlement rate: a leading determinant of structure in an ecological community of the marine intertidal zone. Proc Natl Acad Sci USA 82:3707-3711

Giménez L (2004) Marine community ecology: the importance of trait-mediated effects propagating through complex life cycles. Mar Ecol Prog Ser 283:303-310

Giménez L, Dick S (2007) Settlement of shore crab Carcinus maenas on a mesotidal open habitat in the context of transport processes. Mar Ecol Prog Ser 338:159-168

Heisenberg W (1927) Anschaulicher Inhalt der quantenmechanischen Kinematik. Z Phys 43:172-198

Heisenberg W (1959). Wandlungen in den Grundlagen der Naturwissenschaft. Hirzel Verlag, Stuttgart

Hendler G, Baldwin C, Smith D, Thacker E (1999) Planktonic dispersal of juvenile brittle stars (Echinodermata: Ophi- uroidea) on a Cabibbean reef. Bull Mar Sci 65:283-288

> Hunt H, Scheibling R (1997) Role of early post-settlement mortality in recruitment of benthic marine invertebrates. Mar Ecol Prog Ser 155:269-301

Irisson JO, LeVan A, De Lara M, Planes S (2004) Strategies and trajectories of coral reef fish larvae optimizing selfrecruitment. J Theor Biol 227:205-218

> Jenkins S (2005) Larval habitat selection, not larval supply, determines settlement patterns and adult distribution in two chthamalid barnacles. J Anim Ecol 74:893-904

> Jenkins S, Åberg P, Cervin G, Coleman R and others (2000) Spatial and temporal variation in the settlement and recruitment of the intertidal barnacle Semibalanus balanoides L. (Crustacea: Cirripedia) over a European scale. J Exp Mar Biol Ecol 243:209-225

> Jones G, Milicich M, Emslie M, Lunow C (1999) Self-recruitment in a coral reef fish population. Nature 402:802-804

Keough M, Downes B (1982) Recruitment of marine invertebrates: the role of active larval choices and early mortality. Oecologia 54:348-352

Legendre P, Legendre L (1998). Numerical ecology, 2nd English edn. Elsevier, Amsterdam

> Levin S (1992) The problem of pattern and scale in ecology. Ecology 73:1943-1967

Levin L (2006) Recent progress in understanding larval dispersal: new directions and digressions. Integr Comp Biol $46: 282-297$

Menge B (2000) Recruitment vs. post-recruitment processes as determinants of barnacle population abundance. Ecol Monogr 70:265-288

Moksnes P, Wennhage H (2001) Methods for estimating decapod larval supply and settlement: importance of larval behavior and developmental stage. Mar Ecol Prog Ser 209:257-273

Moksnes PO, Hedvall O, Reinwald T (2003) Settlement behaviour in shore crabs Carcinus maenas: Why do postlarvae emigrate from nursery habitats? Mar Ecol Prog Ser 250:215-230

Morgan G, Phillips B, Joll L (1982) Stock and recruitment relationships in Panulirus cygnus, the commercial rock (spiny) lobster of western Australia. Fish Bull (US) 80: 475-486

Olivier F, Retière C (2006) How to leave or stay on the substratum when you can't swim? Evidence of the role of mucus thread secretion by postlarvae of Pectinaria koreni (Malmgren) in still water and flume experiments. Aquat Ecol 40:503-519

Pineda J (2000) Linking larval settlement to larval transport: assumptions, potentials, and pitfalls. Oceanogr Eastern Pac 1:61-81

Raimondi P (1990) Patterns, mechanisms, consequences of variability in settlement and recruitment of an intertidal barnacle. Ecol Monogr 60:283-309

> Roughgarden J, Gaines S, Possingham H (1988) Recruitment dynamics in complex life cycles. Science 241:1460-1466

Schneider D (1994) Quantitative ecology. Spatial and temporal scaling. Academic Press, London

Shanks A (1995). Mechanisms of cross-shelf dispersal in larval invertebrates and fish. In: McEdward L (ed) Ecology of marine invertebrate larvae. CRC, London, p 323-67

> Valles H, Kramer D, Hunte W (2006) A standard unit for monitoring recruitment of fishes to coral reef rubble. J Exp Mar Biol Ecol 336:171-183 